\title{
Western Faculty Profile: Dr. John Di Guglielmo
}

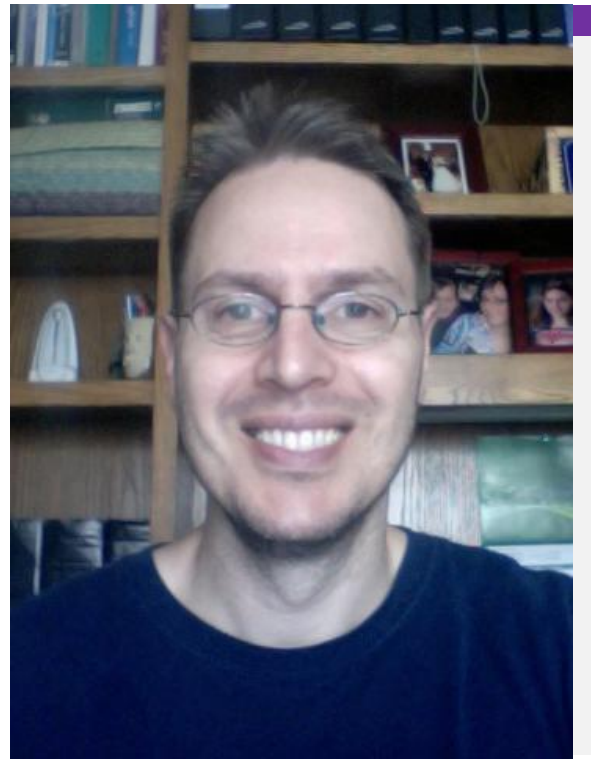

\section{Background}

Dr. John Di Guglielmo was born and raised in Montreal, where he completed his BSc and PhD degrees in Biochemistry at McGill University. During this time, he discovered and grew his passion for conducting basic cancer research. After his post doctorate fellowship at the Samuel Lunenfeld Research Institute (Mount Sinai Hospital, Toronto, ON), Dr. Di Guglielmo came to Western University as an Assistant Professor. Today, he is an Associate Professor in the Physiology and Pharmacology department at Western's Schulich School of Medicine and Dentistry. Cheryl Yip, an Academic Affairs Coordinator for WURJHNS, had the opportunity to interview Dr. Di Guglielmo to learn more about his career in research.

What kind of discoveries do researchers in science make throughout their careers? The immediate and most obvious answer is scientific discoveries related to the researcher's field. There exists, however, a second answer that's often forgotten: a career in research requires much self-discovery and the drive to push yourself to never stop learning.

Dr. John Di Guglielmo didn't always know he would end up choosing research as his career, although he had always known that he wanted to learn more about cancer. In fact, he had never really considered research at all until he was exposed to it during his fourth year independent research project in his undergraduate program. There, he discovered his passion for research. "I loved it," Dr. Di Guglielmo recalls, "I loved the people, the project, the supervisor, and it was some of the most fun l'd had in years." Despite having taken other lab courses in his undergraduate years, Dr. Di Guglielmo credits the fourth year research project as the "eye opener" due to the independence he was given in the lab. "They would show me how to do a technique," explains Dr. Di Guglielmo, "and the rest would be up to me to come up with the experiments. Every day was different and exciting and I realized that this was what I wanted to do."

Figuring out the field he wanted to get into was not an immediate realization either. "I've always known that I wanted to study cancer," says Dr. Di Guglielmo, "there may have been tangents along the way, but I was always following the flow toward working on cancer." During his $\mathrm{PhD}$, his focus was Receptor Tyrosine Kinases, but when he moved onto his post doc, he decided he wanted to try something new and focused on the regulation of Ser/Thr kinase signaling. This is when he started working on the Transforming Growth Factor $\beta$ (TGF $\beta$ ) superfamily of proteins.

What is happening inside a tumour cell? Today, Dr. Di Guglielmo's lab tries to answer these questions on a molecular level and focuses on two main areas. The first is TGF $\beta$ biology in cancer. "The TGF $\beta$ protein has this 'Jekyll and Hyde' role in the cell," explains Dr. Di Guglielmo. In normal cells, TGF $\beta$ causes apoptosis, but in tumour cells, it causes cells to undergo a process called epithelial to mesenchymal transition and metastasize. "What we're trying to figure out is why? What causes the switch? And how can we stop it?" The second area of Dr. Di Guglielmo's lab is more pharmacological, looking at synthetic derivatives of oleanolic acid, which is a naturally occurring triterpenoid found in olive plants. These triterpenoids are potential anti-inflammatory and anti-tumour drugs. Dr. Di Guglielmo's lab seeks to understand how these compounds work by looking at what they target in the cell molecularly. To answer these questions, some of the techniques that are employed his lab include Western blotting, immunofluorescence microscopy, cell growth assays, and migration assays. 
All of the research in Dr. Di Guglielmo's lab, and all other labs for that matter, are very specialized, potentially making it very intimidating for an undergraduate student who is unsure of how to step into the world of research. However, students should not shy away from research at the thought of specialization.

"Take this target diagram of the human knowledge base" (Figure 1) ${ }^{1}$ Dr. Di Guglielmo draws, "with this area in the middle being basic human knowledge. When you're in high school, there is a bit of expansion of your knowledge. Say the largest circle that encompasses everything in the diagram is all of human knowledge. The more you direct yourself into higher education and research, the more you specialize to the point where you are that small blip [labelled "higher education" and "specialization"] in human knowledge. Every scientist out there is specialized at a different point in this circle and, together, we're trying to expand all of human knowledge by focusing on our blip in the circle. What students should realize, then, that every scientist's specialization fits into a bigger picture. Even when you're completing projects as a graduate student, you are constantly being exposed to broader concepts to help you understand how your project fits into that bigger picture."

For Dr. Di Guglielmo, that broader concept and main interest is studying cancer. If a student is able to start by identifying the broader concept they are interested in, it will make it much easier when asking professors to take you on as a research assistant. First, a student should figure out what their main interest is and find Professors that specialize within that main interest. Dr. Di Guglielmo suggests that after the initial step of looking at the web page of a Professor, try to pick up some of the key words mentioned and look them up. Dr. Di Gugliemo says that "even YouTube can help a lot - there will be a video of someone explaining it well, whether it is a lecturer or a pharmaceutical company information movie explaining it to the general public." Next, it is important to try to fit what the Professor does back into the broader concept you are interested in. Rather than trying to come up with an intelligent question about their field, it is more important to show the Professor "your genuine interest in the subject matter, as well as trying new ideas within it."

What, then, are some essential qualities a researcher should have? "Curiosity," answers Dr. Di Guglielmo, "patience, and persistence. Intelligence is important, too, but not number one." Another important quality is the ability to follow instructions carefully. "It's a lot like baking," says Dr. Di Guglielmo, "but more complicated. If you can follow a complicated recipe to the tee, then you would be able to run a gel or do a Western blot." However, how does a student find out if they're suited for research? Dr. Di Guglielmo understands that "you really don't know if research is right for you until you've tried it." As an undergraduate student, the best thing to do is to get experience in a lab that they would enjoy being in. There really is no knowing whether or not research is right for someone until they've tried, so don't be afraid to get started. There is nothing to lose - even if its not a scientific discovery, you are guaranteed to discover more about yourself!

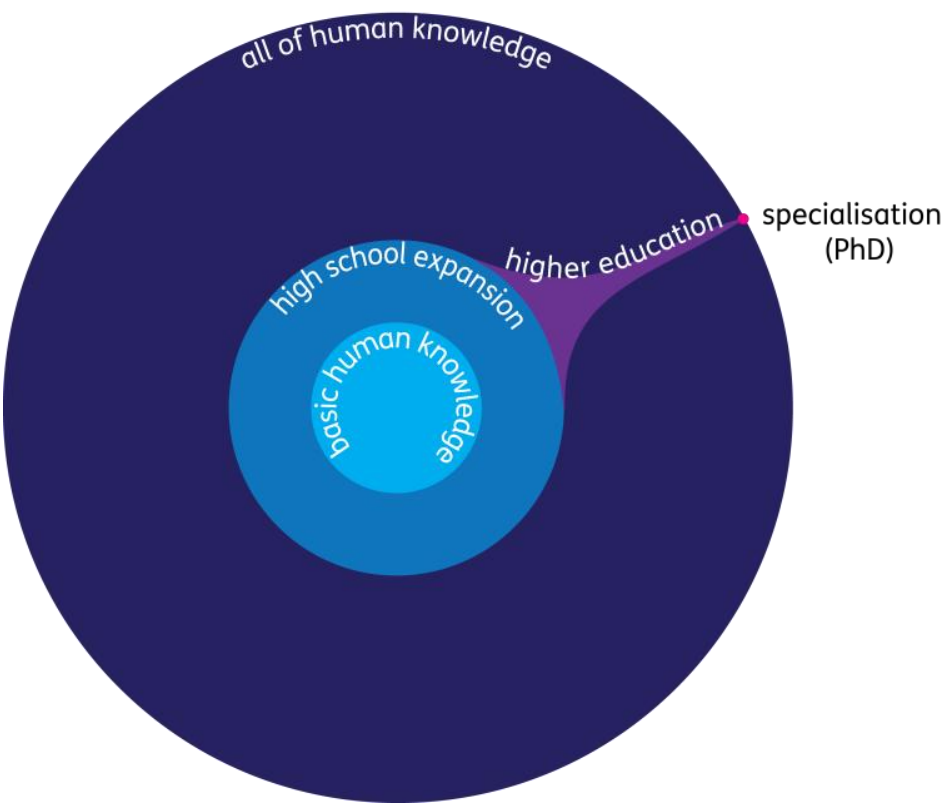

To read more on Dr. Di Guglielmo's research, please visit his website at:

http://www.uwo.ca/physpharm/faculty/diguglielm

o john.html

\section{References}

1. Might M. The illustrated Guide to a PhD. Matt Might: Associate Professor Presidential Scholar [document on the Internet]. Utah: University of Utah; 2015. Available from: http://matt.might.net/articles/phd-school-in-pictures/ and http://matt.might.net/).

Figure 1: Human knowledge base specialization. 